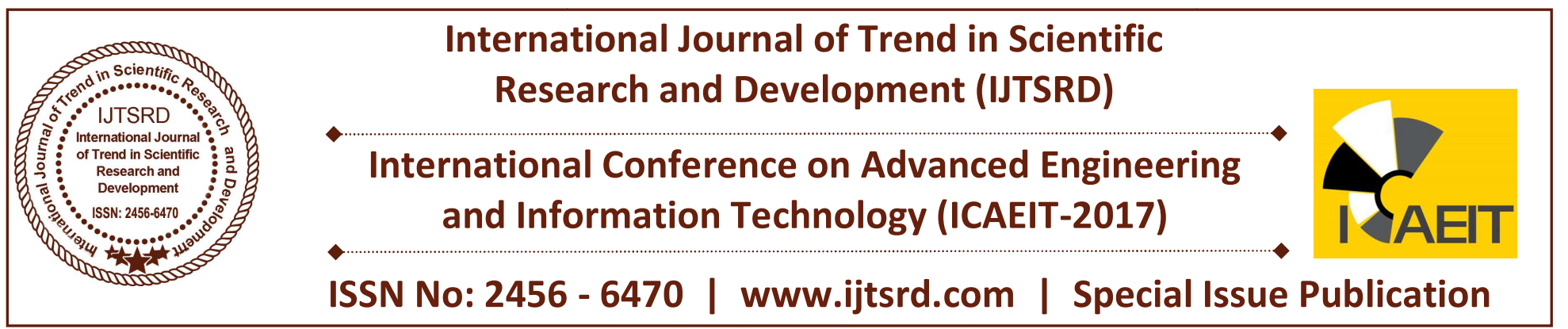

\title{
Performance Evaluation of International Airline Websites Quality using Fuzzy Analytical Hierarchy Process Model
}

\author{
Kayalvizhi Subramanian \\ Faculty of Built Environment, \\ Linton University College, \\ Negeri Sembilan, \\ Malaysia
}

\author{
Gunasekar Thangarasu \\ Department of Computer and \\ Information Science, Universiti \\ Teknologi PETRONAS, \\ Perak, Malaysia
}

\author{
Dr. Mia Torres Dela Cruz \\ Faculty of Engineering and \\ Technology, Linton University \\ College, Negeri Sembilan, \\ Malaysia
}

\section{ABSTRACT}

Statistics play a critical role in any modern use of technology in science and industry. Statistical concepts and methods are developed and applied in the information technology industry for various problems. In order to monitor the quality of products, to plan effective and efficient designs to improve standards, to test and analyze the quality of items produced. The increased attention paid to these problems and accompanying new statistical methodologies, has created an active and valuable new area of research application-industrial statistics. There is a statistical mechanism for measuring the effects of the web page component towards the performance and quality of the website. Every web page design has their own characteristics and this characteristic has drawbacks and benefits. This study focuses on evaluating the quality of international airline websites with sample of five airways. Examined many dimensions of quality, and each dimension has been measured by specific online test using a series of diagnostic tools. The authors propose a methodology for evaluating the airline website quality based on fuzzy analytical hierarchy process model (FAHPM). The result of this study confirmed that more effort is required to meet with these criteria in the context of website design.

Keywords: Statistics, Airlines, Diagnostic, Quality and Performance.

\section{INTRODUCTION}

The quality of the website makes a website profitable, user friendly and easy accessible. A good website offers useful and reliable information, providing good design and visual representation to meet the users' needs and expectation. This can be done by defining the measurable website criteria. The quality of the website could be measured from two perspectives: software developers and end- users. Website quality has been defined by many characteristics such as information science, information technology, mediated communication and so on [1]. The challenge of the measurement is how to create a method that will guide the internet user to evaluate website very easily. The airline website measurement of quality process takes lots of time and concentration from the professional. Nevertheless, may not expect the same time and concentration from the public. The evaluation of a website in terms of quality lacks a single point definition. It is the combination of various factors such as aesthetic, logic, technology and so on. There are many scopes of quality, and each measure will pertain to a particular website in varying degrees, namely (a) functionality, (b) reliability, (c) efficiency, (d) usability, (e) portability and, (f) maintainability [2].

The functionality is the interactive part of the site that which allows the visitor to respond in some way. All the components and links of the website should work properly. The user expects each link to be valid. Broken links on the web page always downgrade the quality of the website [3]. A website without functionality is a one-way street. It is pointless to have a website that does not provide any form of visitor 
interactivity. The second factor is reliability; it is difficult to define the term objectively. Website reliability is the probability of failure-free operation of the website within a specified environment for a specified purpose. In the other hand reliability is ameasure of how well the users perceive a website provides the required services. For each failure identified, describe the acceptable reliability using an Appropriate metric. Next efficiency, it means more Effective design and simple process of digesting information on a website. Today's web users are sophisticated and they know that there are plenty of other websites available to fulfil their needs. Leaving unfulfilling website is the first line of defence when someone encounters the slightest difficulty. A website server should respond to a browser request within certain parameters. The Skytrax rankings are based on the impressions of 19.87 million travellers from 105 different countries. Business Insider 2016 [4] reported that Skytrax world airline star rating is the recognized global airline rating system that classifies airlines by the quality of their service. The survey, which covered more than 325 airlines, measured 49 parameters ranging from the quality of service. Table1 showed the ranking of airlines based on report publishes by London based consultancy firm Skytrax in 2017.

Table 1: Top seven airlines website based on the survey

\begin{tabular}{|c|l|c|c|}
\hline $\begin{array}{c}\text { Sl. } \\
\text { No }\end{array}$ & \multicolumn{1}{|c|}{ Name of Airline } & Websites & Rank \\
\hline 1 & Qatar Airways & - & 1 \\
\hline 2 & Singapore Airlines & - & 2 \\
\hline 3 & Nippon Airways & - & 3 \\
\hline 4 & Emirates Airways & - & 4 \\
\hline 5 & Cathay Pacific Airways & - & 5 \\
\hline 6 & Eva Airlines & - & 6 \\
\hline 7 & Lufthansa Airlines & - & 7 \\
\hline
\end{tabular}

The usability of a website is one of the most important factors that make or break the site. User - centric design has become the standard approach for successful and profit-focused web design. If airlines website home page fails to clearly state what a company offers and what users can on the site, people often leave the site. If users get lost on a website, they will probably get frustrated and leave. Portability means the ability to move the website from one Host Company to another and the platform that runs the site will work on the new host. If a web company builds the site on their own proprietary platform and the platform itself is not transferable, then the website would not work properly if the user tries to move it somewhere else. Maintainability is not an initial development, but in its on-going maintenance, fixing bugs, keeping its system operational, investigating failures, adapting it to new platforms, modifying it for new cases, repaying technical debt, and adding new features [5]. Figure-1 shows the various factors of website quality.

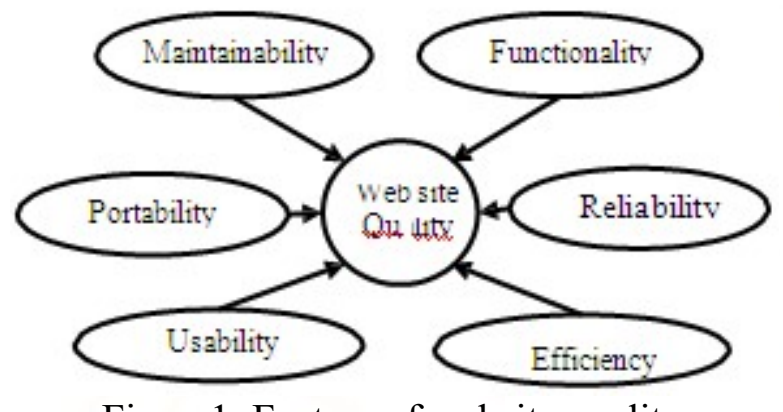

Figure1. Factors of website quality

\section{Background of the Study}

The website evaluation, most studies focus on the factors for successful websites based on the user's perspective. These studies search for design and content elements of a successful website using the exploratory study. The main areas of the website quality evaluation are functional, usability, efficiency and reliability [6]. Website architecture is classified into two main areas which are content and design [7] and each category is specified into evaluation criteria according to the characteristics and perception of a website.

The website evaluation model is based on the study of the user-centered development and evaluation approach. Best websites selected by experts and users are investigated in order to identify the common characteristics of them The criteria include structure, content, navigation, visual design, functionality and interactivity. The new methodology which is Web Tango introduced in the previous study. It is a website quality check tool, which proposes to help non- professional designers to develop their sites using quantitative measures of the website [8].

An automated website evaluation tool is developed by applying the software quality. The function of an automated website evaluation tool consists of capture, analysis and critique of website data [9]. This tool is widely used in practice and some of the examples include A-Prompt, Watch Fire Bobby, Usable Net LIFT, W3c HTML Validator, and National Institute 
of Standards and Technology (NIST). NetRaker, another evaluation tool, developed an online survey which allows users to answer the survey while using the website. It collects and analyses user survey data of a website [10].

Every web page design has their own characteristic and this characteristic has drawbacks and benefits. There is a mechanism for measuring the effects of web page component towards the performance and quality of the website. This mechanism will measure size, component and time needed by the client for downloading a website. The main factor that will influence this download time are page size, number and types of component and number of servers from the accessed web. Research conducted by IBM can be used as a standard for performance measurement of quality. A standard international download time for this performance can be used as a reference to categories the tested web page. Automation of the testing for website quality is a new chance and a new method and should be applied for testing the quality of the website. For leveraging the effectiveness of the continuous quality improvement, the developer community has been aggressive in attaining TQM strategies by implementing ISO 9001: 2000 standards [10].

Broken links can give bad impact for the credibility of a website. Credibility is especially important in the World Wide Web, because transaction between customer and seller is not on the spot and the risk of fraud is several times higher. The customers would certainly choose to buy from a website that looks professional [11]. Table-2 displayed the standard of the website performance.

Table 2: Standard of the website performance

\begin{tabular}{|c|c|c|}
\hline S.No & Tested Factors & $\begin{array}{c}\text { Quality } \\
\text { Standard }\end{array}$ \\
\hline 1 & Average server response time & $<0.5 \mathrm{Sec}$ \\
\hline 2 & $\begin{array}{c}\text { Number of components per } \\
\text { page }\end{array}$ & $\begin{array}{c}<20 \\
\text { Objects }\end{array}$ \\
\hline 3 & Web page loading time & $<30 \mathrm{Sec}$ \\
\hline 4 & Web page size in byte & $<64 \mathrm{~KB}$ \\
\hline
\end{tabular}

\section{Methodology}

This study consists of four stages, start with problem identification followed by research procedure and data collection and ended with analysis of data. This research examined the national airlines portals of a selected number of countries in global: Qatar Airways, Singapore Airlines, Emirates Airways, Cathay Pacific Airways and Lufthansa airways.

The data have been taken from June 2016 until end of August 2016. Using website diagnostic tools and a selected method which is fuzzy analytical hierarchy process model (FAHP). The data were analyzed by using non-parametric statistical test. The researcher used widely available website performance tool and web page speed Analyzer online

http://www.websiteoptimization.com. service available web page online tools that researcher used for testing quality is http://vaidator.w3.org/checklink which was utilized in order to monitor broken links in the HTML code of the portals.

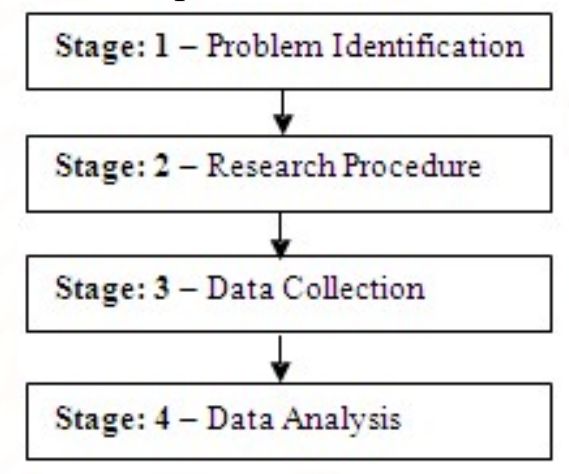

Figure2. Research stages

To get the data for this research, the researcher examined the airlines websites' from five countries: Qatar (www.qatarairways.com), Singapore (www.singaporeair.com),

(www.emirates.com), Hong Kong (www.cathaypacific.com) and German (www.lufthansa.com). The airlines' websites were selected based on the result of a survey conducted by Skytrax Company.

\subsection{Analytical hierarchy process}

Analytical hierarchy process (AHP) is a structured technique for organizing and analyzing complex decisions, based on mathematics. It was originally designed by Saaty [12] to solve complicated multicriteria decision problem, beside that AHP is appropriate whenever a target is obviously declared and a set of relevant criteria and alternatives are offered. AHP has been proposed for determining the best website to support researcher through the decision- making activity, which aims to determine the best website among a pool of airlines website. 
AHP is a popular model to aggregate multiple criteria for decision-making [13]. In AHP, the problems usually presented in a hierarchical structure and the decision- maker is guided throughout a subsequent series of pairwise comparisons to express the relative strength of the elements in the hierarchy.

In general, the hierarchy structure encompasses of three levels, where the top level represents the goal, and the lowest level has the website under consideration. The intermediate level contains the criteria under which each website is evaluated. In the constantly fluctuating of the website, the evaluation cannot survive without comprehensive quality factor identification and evaluation. The AHP methodology is demonstrated by applying it to the quality factors with the airlines website problem. Construction of the hierarchy is the first step in the problem-solving process.

\subsection{Fuzzy analytical hierarchy process model (FAHPM)}

In spite of the popularity of AHP, this method is often criticized for its inability to adequately handle the inherent uncertainty and imprecision associated with the mapping of the decision-maker's perception of exact numbers [14]. Since fuzziness and vagueness are common characteristics in many decision-making problems, a fuzzy AHP (FAHP) method should be able to tolerate vagueness or ambiguity [15]. In other word the conventional AHP approach may not fully reflect a style of human thinking because the decision makers usually feel more confident to give interval judgments rather than expressing their judgments in the form of single numeric values and so FAHP is capable of capturing a human's appraisal of ambiguity when complex multi-attribute decision making problems are considered [16]. This ability comes to exist when the crisp judgments transformed into fuzzy judgments. Zadeh [17] published his work Fuzzy Sets, which described the mathematics of fuzzy set theory. This theory, which was a generalization of classical set theory, allowed the membership functions to operate over the range of real numbers $[0,1]$. The main characteristic of fuzziness is the grouping of individuals into classes that do not have sharply defined boundaries [18]. The uncertain comparison, judgment can be represented by the fuzzy number. A triangular fuzzy number is the special class of the fuzzy number whose membership defined by three real numbers, expressed as $(1, \mathrm{~m}$, and $\mathrm{u})$. The triangular fuzzy numbers are represented as follows Figure.3.

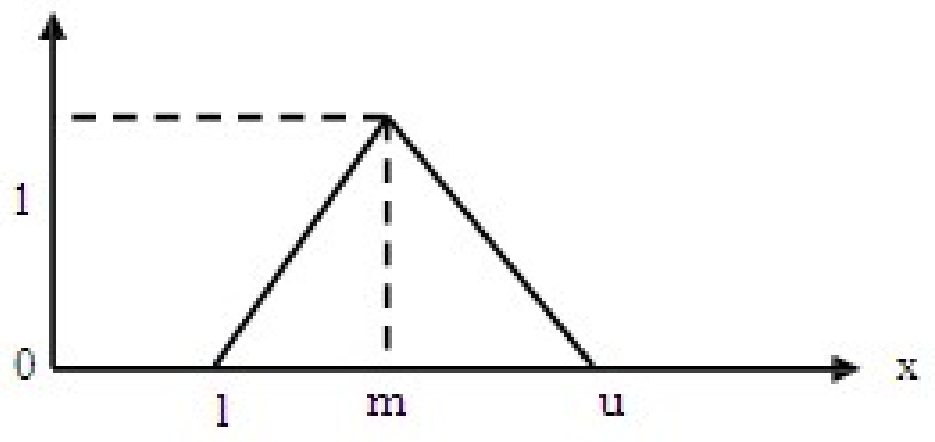

Figure3. Fuzzy triangular number

In this case, the goal of an AHP and the also FAHP decision is to select the best airlines website during the first level. Load time, response time, page link, frequency of update, traffic, and design, and size, number of items, accessibility error, markup validation and broken link are the evaluation criteria during the second level of the hierarchy.

\section{Result and Discussion}

The result of the website quality test based on load time, response time, page rank, frequency of update, traffic, design optimization, size, number of times, accessibility error, mark-up validation and broken link are also displayed in Table-3. In the table-3 alphabets $\mathrm{A}-\mathrm{K}$ and $\mathrm{W}$ represents the following.
A - Load time
B - Response Time
C - Page link
D - Frequency of update
E - Traffic
F - Design optimization
G - Size
$\mathrm{H}$ - Number of times
I - Accessibility error
J - Markup validation
K - Broken link
W - Weight

$\begin{array}{ll}1 & \text { - Qatar airways } \\ 2 & \text { - Singapore airlines } \\ 3 & \text { - Emirates airways } \\ 4 & \text { - Cathay airways } \\ 5 & \text { - Lufthansa airways }\end{array}$


Table 3: Weight criteria and Websites

\begin{tabular}{|c|c|c|c|c|c|c|}
\hline Criteria & $\mathbf{1}$ & $\mathbf{2}$ & $\mathbf{3}$ & $\mathbf{4}$ & $\mathbf{5}$ & $\mathbf{W}$ \\
\hline A & 0.000 & 0.000 & 0.013 & 0.000 & 0.429 & 0.271 \\
\hline B & 0.276 & 0.165 & 0.000 & 0.401 & 0.048 & 0.262 \\
\hline D & 0.216 & 0.180 & 0.000 & 0.200 & 0.100 & 0.012 \\
\hline E & 0.265 & 0.324 & 0.000 & 0.310 & 0.076 & 0.001 \\
\hline F & 0.000 & 0.000 & 0.203 & 0.417 & 0.276 & 0.000 \\
\hline G & 0.000 & 0.000 & 0.000 & 0.000 & 0.471 & 0.000 \\
\hline H & 0.000 & 0.010 & 0.000 & 0.000 & 0.500 & 0.000 \\
\hline I & 0.125 & 0.122 & 0.136 & 0.000 & 0.213 & 0.000 \\
\hline J & 0.000 & 0.000 & 0.460 & 0.000 & 0.302 & 0.000 \\
\hline K & 0.100 & 0.121 & 0.285 & 0.000 & 0.184 & 0.000 \\
\hline
\end{tabular}

Table-4 depicts the final scores of website. The most important thing is regarding the final results, the website which has the highest score is suggested as the best website for the proposed FAHP model. The website which has the highest score is suggested as the best website for the proposed FAHP model. The Cathay Pacific website has the highest score of 0.45596 in comparison with the rest of airline websites. As a result, the proposed FAHP model rank for airline website is: Cathay pacific airlines (score: 0.45596), Singapore airlines (score: 0.34809), Qatar Airways (score: 0.24943), Emirate airways (score: 0.13651) and the last rank is Lufthansa airlines (score: 0.12046). Table-5 has shown the final rank which obtained from FAHPM.

Table 4: Final result of FAHPM

\begin{tabular}{|c|c|c|c|c|c|}
\hline Criteria & 1 & 2 & 3 & 4 & 5 \\
\hline A & 0.10000 & 0.28233 & 0.11371 & 0.00000 & 0.11950 \\
\hline B & 0.07620 & 0.04340 & 0.00000 & 0.11061 & 0.01401 \\
\hline C & 0.05900 & 0.00000 & 0.00000 & 0.42524 & 0.00000 \\
\hline E & 0.00143 & 0.02180 & 0.00000 & 0.00011 & 0.00095 \\
\hline F & 0.00000 & 0.00056 & 0.00000 & 0.00090 & 0.00000 \\
\hline G & 0.00000 & 0.00000 & 0.00000 & 0.00000 & 0.00000 \\
\hline H & 0.00000 & 0.01000 & 0.00000 & 0.00000 & 0.00000 \\
\hline I & 0.00000 & 0.00000 & 0.00000 & 0.00000 & 0.00000 \\
\hline J & 0.00000 & 0.00000 & 0.00000 & 0.00000 & 0.00000 \\
\hline K & 0.00000 & 0.00000 & 0.00000 & 0.00000 & 0.00000 \\
\hline Total & 0.24943 & 0.34809 & 0.13651 & 0.45596 & 0.12046 \\
\hline
\end{tabular}

Table 5: Final rank from FAHPM

\begin{tabular}{|c|c|c|c|}
\hline $\begin{array}{c}\text { Sl. } \\
\text { No }\end{array}$ & Name of Airline & Websites & Rank \\
\hline 1 & Cathay Pacific Airways & - & 1 \\
\hline 2 & Singapore Airlines & - & 2 \\
\hline 3 & Qatar Airways & - & 3 \\
\hline 4 & Emirates Airways & - & 4 \\
\hline 5 & Lufthansa Airlines & - & 5 \\
\hline
\end{tabular}

\section{Conclusion}

In this paper, the author evaluates the quality of international airline websites with sample of five airways namely, Qatar airways, Singapore airlines, emirates airways, Cathay pacific airways and Lufthansa airlines. Examined many dimensions of quality, and each dimension has been measured by specific test using a series of online diagnostic tools. The result of this study confirmed that more effort is required to meet with these criteria in the context of website design. The author proposed fuzzy analytical hierarchic process model as a methodology for determining and evaluate the best airline website based on many criteria of website quality. Regarding the final results, the website which has the highest score is suggested as the best website for the proposed FAHP model. The study result suggests that web designers responsible for airlines website should follow and encourage the use of recognized guidelines when designing a website. 
International Journal of Trend in Scientific Research and Development (IJTSRD) | ISSN: 2456-647

\section{References}

1. C. Mcinerney, "Establishing and maintaining trust in online system", in M. Williams (Ed), The 21st National online Meeting Information Today, Medford, N. J, 2002.

2. A. B. AL-Badareen, M. H. Selamat, M. A. Jabar, J. Din, S. Turaev, "Users' Perspective of Software Quality", The 10th WSEAS International Conference on Software Engineering, Parallel and Distributed System, PP. 84-89, 2011.

3. F. Mccowen, N. Michael, J. Bollen, "The availability and persistence of web references in D- Lib Magazine", The 5th International Web Archiving Workshop and Digital Preservation (IWAW'05), Viena, 2005.

4. The Top 100 . Airlines of 2017,www.airlinequality.com/info/top-100airlines-2017.

5. A. Kumar, P. S. Grover, R. Kumar, " A quantitative evaluation of aspect-oriented software quality model (AOSQUAMO), SIGSOFT Software Engineering, Notes 34, PP. 1-9, 2009.

6. L. Olsina, D. Godoy, G. J. Lafuente and G. Rossi, "Specifying quality characteristic and attributes for website", in S. Murugesan and Y. Deshpande (Eds), Web Engineering. LNCS, PP. 226-278, 2016

7. E. Huizingh, "The content and design of web sites: an empirical study", Information and Management, Volume No.37, PP. 123-134, 2000.

8. M. Ivory and M. Hearst, "The state of the art in automating usability evaluation of user interfaces". ACM Computing Surveys, Volume No. 33, PP. 470-516.

9. G. Brajnik, "Quality models based on automatic web testing", CHI Workshop, Minneapolis, ACM, 2002.

10. M. Sakthivel, S. R. Devadasan, S. Vinodh, A. Ramesh and S. Shyamsundar, "ISO 9001:2000 based quality information management responsibility system", International Journal of Business Information System, Volume No. 2, PP. 217-237.

11. M. Amerson, G. Fisher, L. Hsiung, L. Krueger and N. Mills, "Design for Performance: Analysis of Download Times for page Elements Suggests Ways to Optimize, Available at: http://www.ibm.com/developerworks/websphere/1 ibrary/techarticle/hipo ds/perform.html.

12. T. Saaty, "The Analytic Hierarchy Process: Planning, Priority Setting Resources Allocation, London: McGraw-Hill, 1980.

13. S. Zahir and R. Sarker, "Optimizing multiobjective location decisions in a supply chain using an AHP- enhanced goal-programming model", International Journal of Logistics System and Management, Volume No. 6, PP. 249-266, 2010 .

14. H. Deng, "Multi-criteria analysis with fuzzy pairwise comparison", IEEE International Fuzzy Systems Conference Proceeding, Seoul, South Korea, Volume No.2, PP. 726-731.

15. A. H. I. Lee, , W. C. Chen, C.J. Chang, "A fuzzy AHP and BSC approach for evaluating performance of IT department in the manufacturing industry in Taiwan", Expert Systems with Applications, Volume No. 34, PP. 96-107, 2008.

16. Y. C. Erensal, T. Oncan, M. L Demircan, "Determining key capabilities in technology management using fuzzy analytic hierarchy process: A case study of Turkey. Information Sciences", Volume No. 176, PP. 2755-2770.

17. L. A. Zadeh, "Fuzzy algorithms", Information and control, Volume No.12, Issue No.2, PP.94-102.

18. N. Balakrishnan, "Statistics for Industry and Technology", McMaster University, Hamilton, Canada, 2013. 